\title{
Salt stress slows down dynamic photosynthesis mainly through osmotic effects on dynamic stomatal behavior
}

\author{
Yuqi Zhang ${ }^{1}$, Elias Kaiser ${ }^{2}$, Tao Li $^{3}$, and L.F.M. Marcelis ${ }^{4}$ \\ ${ }^{1}$ Chinese Academy of Agricultural Sciences Institute of Environment and Sustainable \\ Development in Agriculture \\ ${ }^{2}$ Wageningen University \\ ${ }^{3}$ Affiliation not available \\ ${ }^{4}$ Wageningen UR Greenhouse Horticulture
}

June 2, 2021

\begin{abstract}
Salt stress affects stomatal behavior and photosynthesis, by a combination of osmotic and ionic components, but it is unknown how these components affect photosynthesis dynamics under fluctuating light. Tomato (Solanum lycopersicum) plants were grown using a reference nutrient solution (Control, EC: $2.3 \mathrm{dS} \mathrm{m}-1$ ), the reference containing extra macronutrients (only osmotic effect; EC: $12.6 \mathrm{dS} \mathrm{m}-1$ ), or the reference containing an additional $100 \mathrm{mM} \mathrm{NaCl}$ (osmotic and ionic effects; EC: $12.8 \mathrm{dS}$ m-1). Steady-state and dynamic photosynthesis along with leaf biochemistry were characterized throughout leaf development. Osmotic effects resulted in increased leaf chlorophyll content per unit leaf area, induced stomatal closure along with rapid stomatal responses to changes in light intensity, and limited dynamic but not steady-state photosynthesis. Ionic effects were barely observed in plant growth and dynamic photosynthesis, but led to a reduction in leaf chlorophyll content and photosynthetic capacity in old leaves. Steady-state and dynamic photosynthesis traits decreased with leaf age, due to increases in stomatal and non-stomatal limitations. With increasing leaf age, rates of light-triggered stomatal movement decreased across treatments, which is more strongly for stomatal opening rather than closure. We conclude that osmotic effect strongly impacts dynamic stomatal and photosynthetic behavior under salt stress.
\end{abstract}

\section{Hosted file}

Chapter 3_Osmotic VS Ionic_paper_draft V9.docx available at https://authorea.com/users/ 417597/articles/524631-salt-stress-slows-down-dynamic-photosynthesis-mainly-throughosmotic-effects-on-dynamic-stomatal-behavior 
A

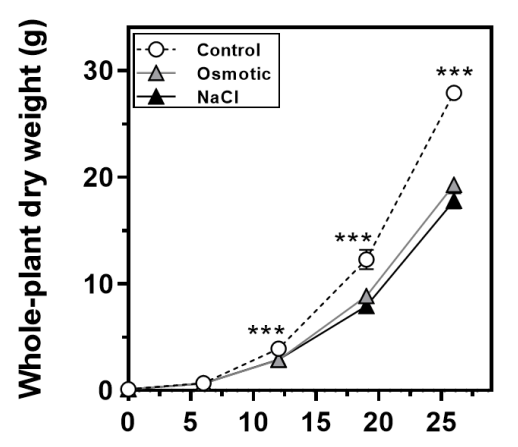

Days after start of treatment
B

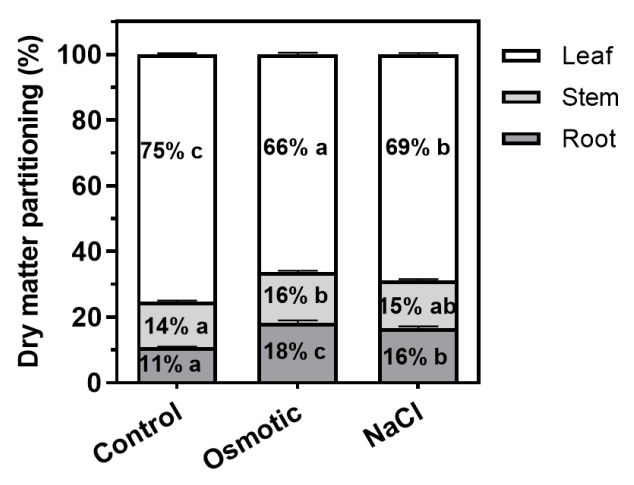

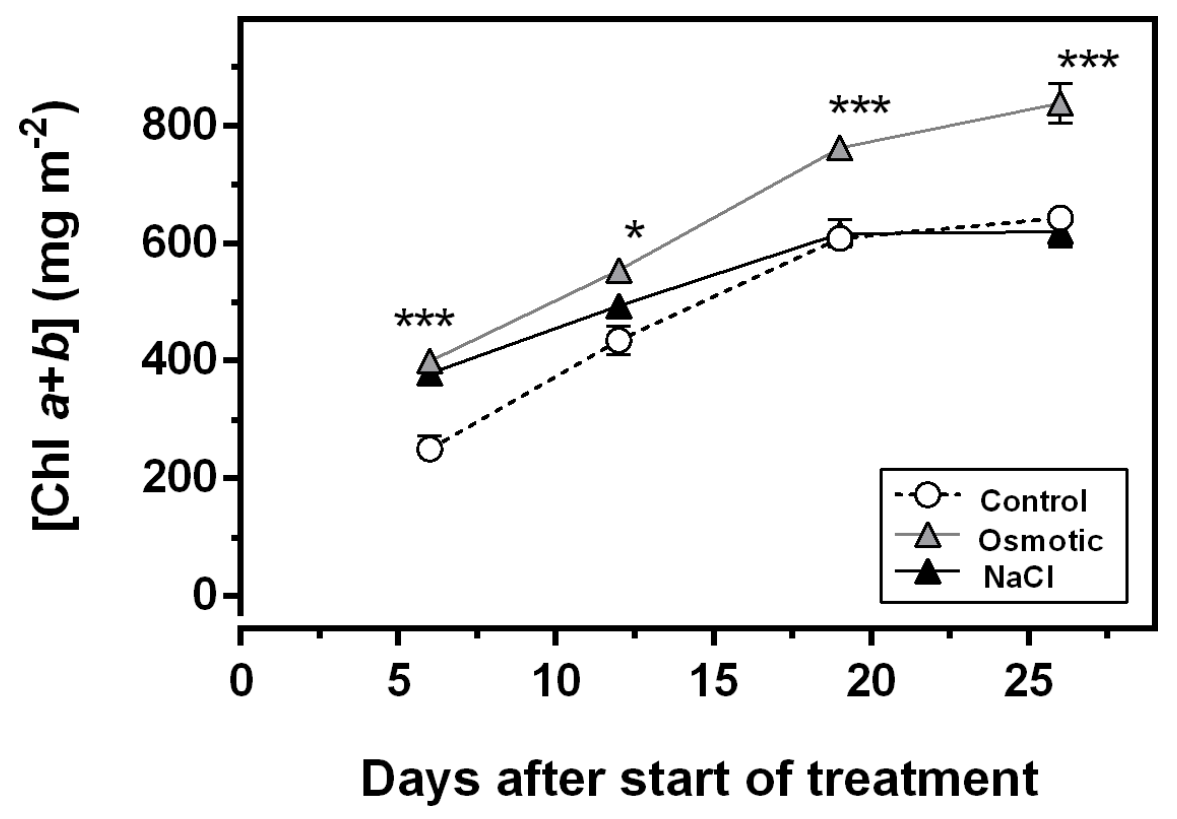



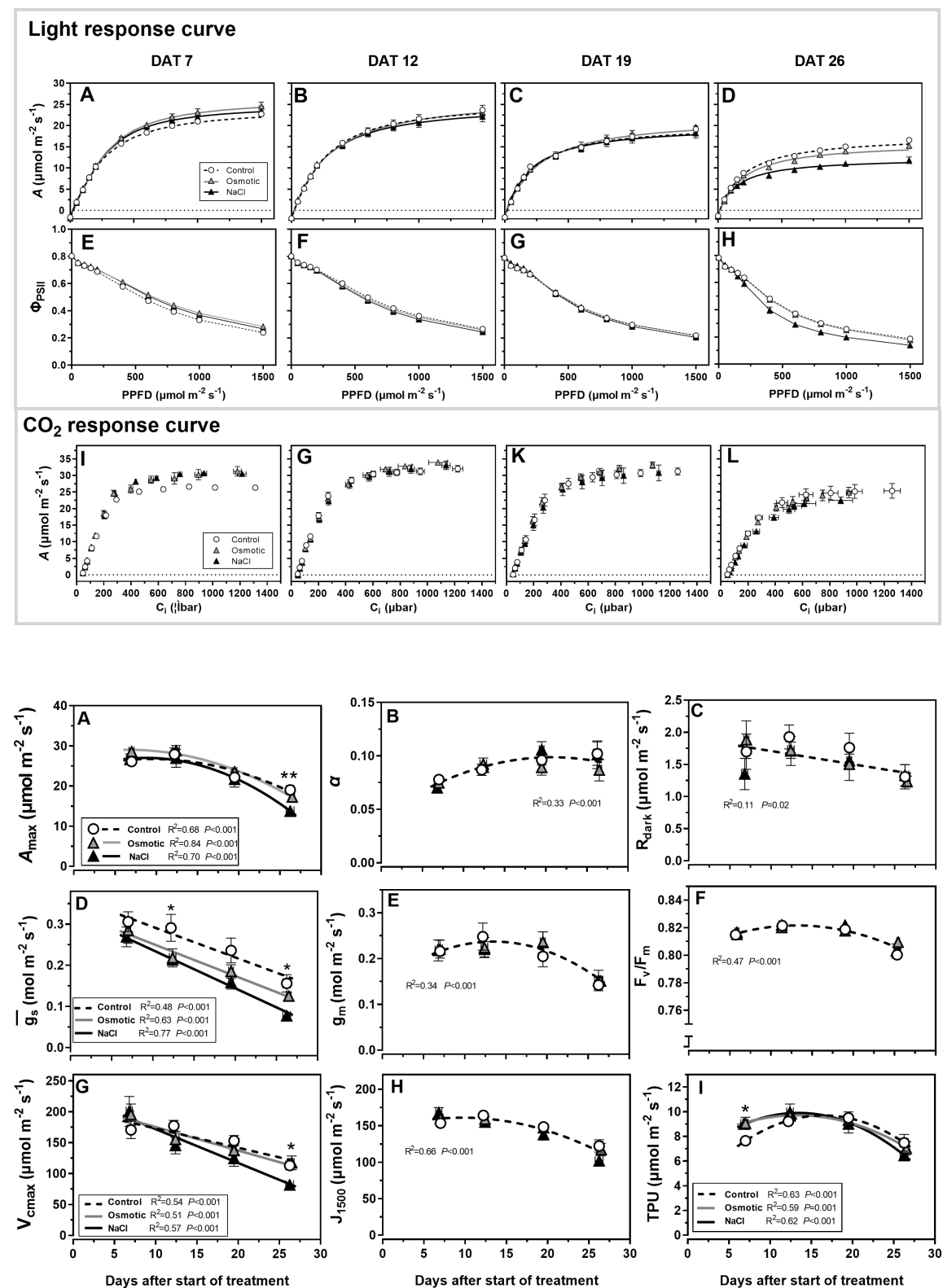


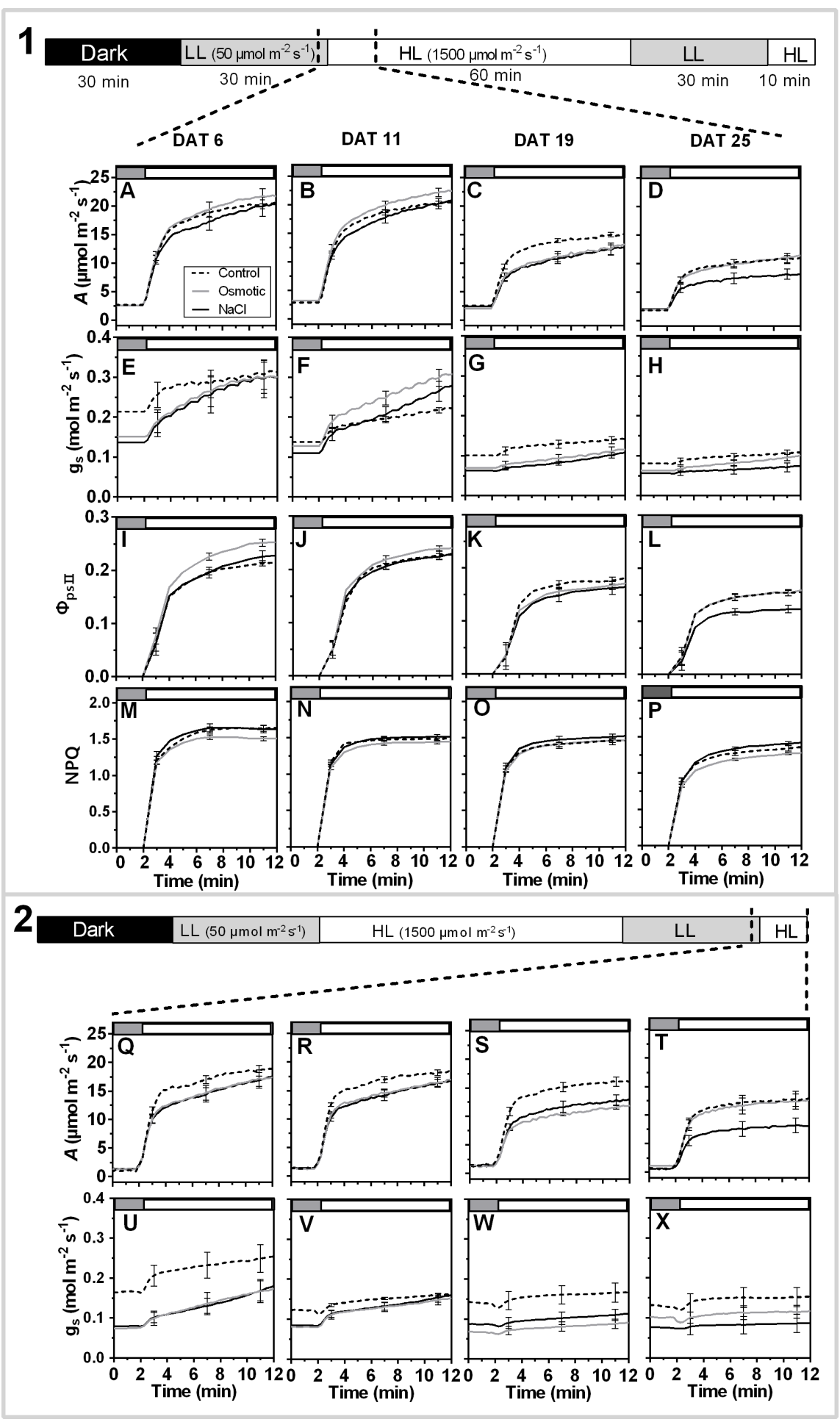



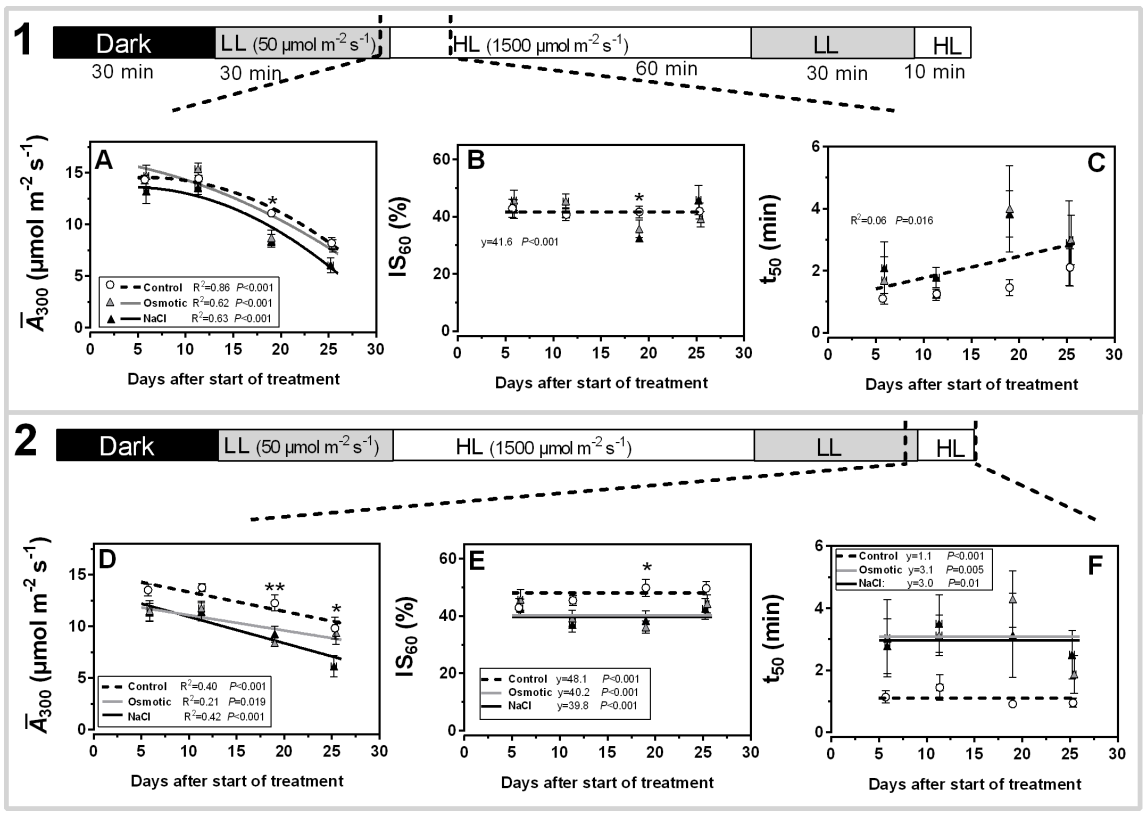

$\square \mathrm{HL}\left(1500 \mu \mathrm{mol} \mathrm{m} \mathrm{s}^{-2}\right) \quad \square \mathrm{LL}\left(50 \mu \mathrm{mol} \mathrm{m}^{-2} \mathrm{~s}^{-1}\right)$

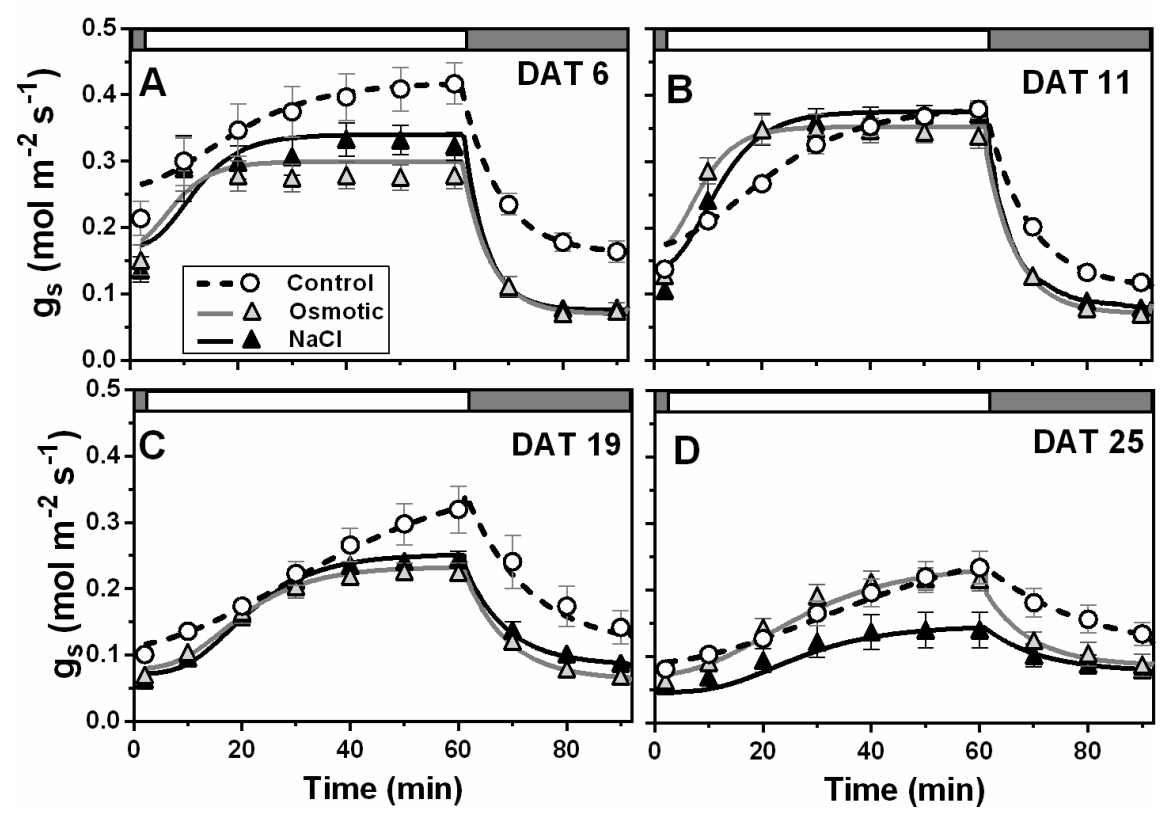



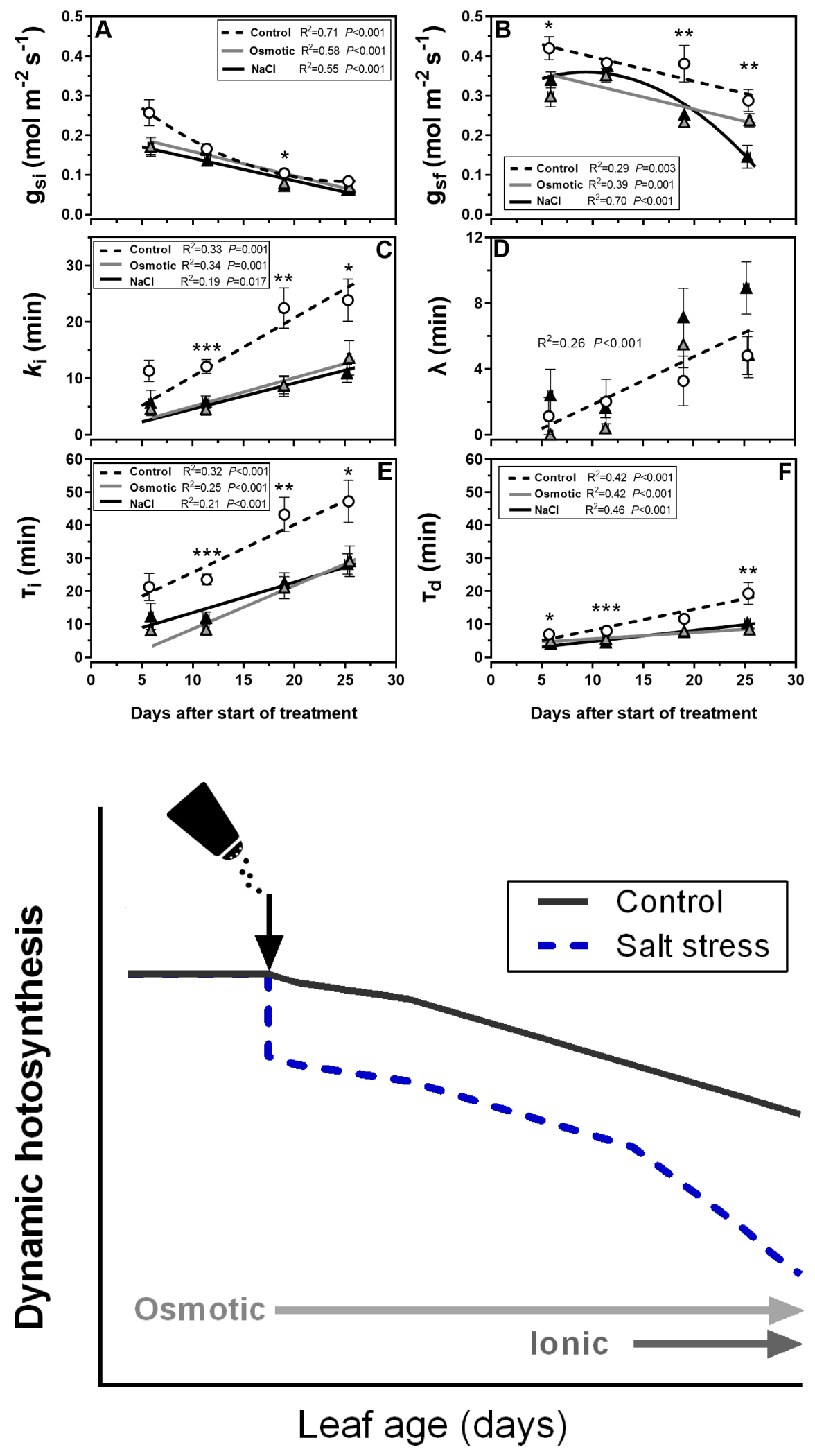